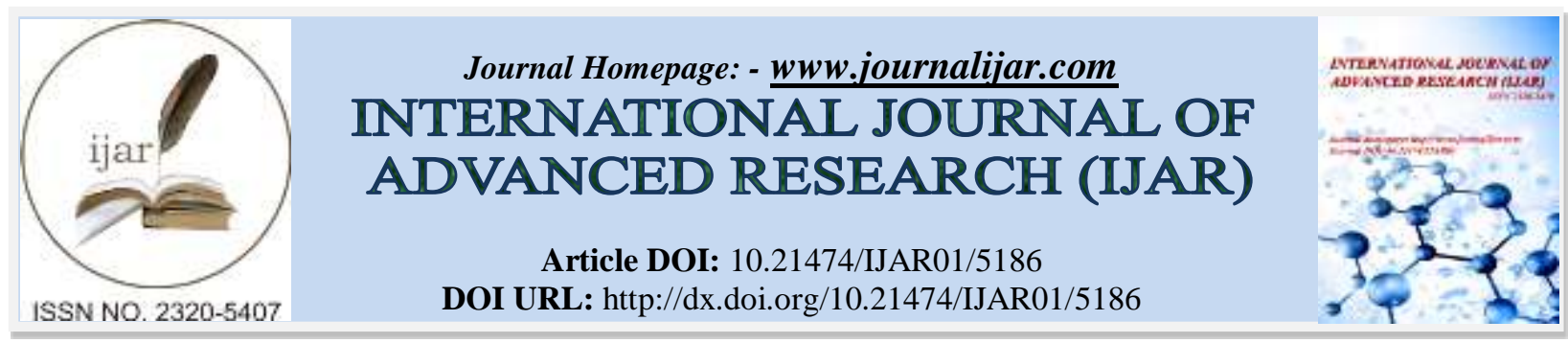

RESEARCH ARTICLE

\title{
EVALUATION OF POSTOPERATIVE COMPLICATION AFTER SURGICAL REMOVAL OF THIRD MOLARS FOLLOWING LOCAL OR SYSTEMIC ADMINISTRATION OF DEXAMETHASONE-A COMPARATIVE STUDY.
}

\author{
Dr. Abhishek harish and Dr. K Padma rayalu andDr. Kishore moturi.
}

\section{Manuscript Info}

Abstract

Manuscript History

Received: 16 June 2017

Final Accepted: 18 July 2017

Published: August 2017

Copy Right, IJAR, 2017,. All rights reserved.

\section{Introduction:-}

The mandibular third molars has the greatest incidence of impaction. The surgical removal of the impacted lower third molar is one of the commonly performed surgery by the oral and maxillofacial facial surgeons.Pain,swelling and discomfort to the patient are inevitable sequelae of inflammation following surgical removal of the impacted teeth. Minimally invasive surgical technique will minimize the sequelae of inflammation but will not prevent them. Therefore, pharmacological intervention is needed to control the extent of inflammation and sequelae such as pain, swelling and trismus.

Inflammatory response to tissue injury is said to be defensive mechanism adapted by the body. The inflammatory response is closely interwined with the process of repair. The inflammatory process is necessary if healing is to occur but often excessive inflammation causes the patient unnecessary pain, swelling and restricted mouth opening in oral cavity.

The research in control of inflammation following minor oral surgery is vast and a never ending process where new drugs are introduced administered and analyzed upon their merits and demerits. The ideal anti-inflammatory agents following removal of third molar should possess ideal properties like alleviation of pain, reduction of edema, early return to function of both the masticatory apparatus and patient's increased inter incisal opening by relieving trismus and promote healing of the immediately adjacent tissues with minimal or no side effects. Steroids, nonsteroidal anti-inflammatory drugs, opioids, enzymes, anti-histamines, long acting local anesthetics, antibiotics have been tried with varying degrees of success ${ }^{33,46}$.

The non-steriodal anti-inflammatory drugs (NSAIDs) from salicylates to recent selective COX inhibitors are used with varying degree of success in oral surgical practice.

The anti-inflammatory action of corticosteroids was first discovered by Hench and co-workers in the treatment of rheumatoid arthritis in 1949. During 1950's researchers demonstrated that hydrocortisone may prevent inflammation following oral surgery ${ }^{1,3,4}$.Hydrocortisone also known as Cortisol are classified as adrenocorticosteroids which are produced by adrenal cortex. Under normal non stressful conditions $15-30 \mathrm{mg}$ per day of hydrocortisone is produced. During stressful conditions 300mg per day of hydrocortisone is produced. For suppression of inflammation, 
exogenous steroids administered in addition to the normal physiological amounts are shown to be of definite help in reducing inflammation and its sequelae.

In 1957 Arth et al. synthesized a new family of steroid compounds containing in common a cyclopentonoperhydrophenanthrine ring with methyl group at the sixteenth carbon position of the nucleus. One of these compounds was Dexamethasone. It is a synthetic, long acting adrenocorticosteroid that exerts basic glucocorticoid action and is approximately 25 times more potent than hydrocortisone, 6 times than of prednisalone, 4 times that of methyl prednisolone and triamcinolone and equipotent to betamethasone. At equipotent antiinflammatory doses it lacks the sodium retaining properties of hydrocortisone.Based on there half life they are classified into short, intermediate and long acting steroids.

Reviewing the past studies of glucocorticosteroid, their clinical results in oral and maxillofacial surgery and potency of dexamethasone among the glucocorticosteroids and to ensure a high local concentration of drug, a comparative study of single injection $4 \mathrm{mg}$ of dexamethasone locally in submucosal region and intravenously into cephalic vein in cases of surgical removal of bilaterally impacted mandibular third molars was undertaken to evaluate and assess the efficacy of the drug in reducing swelling,trismus and pain.Encouraging results in similar study was seen that compared submucosal administration of dexamethasone versus methylprednisolone in third molar surgery ${ }^{51}$.Further a clinical study was conducted to evaluate dose related response of dexamethasone which showed no significant change in postoperative complication following third molar surgery ${ }^{12}$.

\section{Review of Literature:-}

1.ChristianFreudlsperger,TimoDeiss,Jensbodem,MichaelEngel,JeurgenHoffmann;Influ ence of Lower Third Molar Anatomic Position on Post-operative Inflammatory Complications ; JOMS/2012/70/1280-1285: Postoperative Inflammatory Condition, including alveolar Osteris, Surgical site infection and abscess are frequent complications after surgical removal of impacted mandibular third molars. This study reveals a highly significant correlation between the level of difficulty for surgical removal of lower third molars and postoperative inflammatory complication.

2. Anne.E.B.Dan,Torben.H.Thygesen,Else.M.Pinholt;Corticosteroid Administration In Oral And Orthognathic Surgery : A Systemic Review of The Literature and meta-Analysis ; JOMS/2010/68/2207-2220: This study evaluated the effect of corticosteroid administration on edema, analgesia and Neuro-regeneration in conjunction with surgical dental extraction, Orthognathic Surgery and risk of developing side effects, findings suggest that administration of corticosteroids in Oral surgery decreases edema and pain significantly, with no higher risk of infection and with minimum risk of other side effects.

- Imaad Abu-El Naaj,Rafael Braun,YoavLeiser,MichaPeled;Surgical Approach To Impacted Mandibular Third Molars - Operative classification ; JOMS/2010/68/628-633:

The aim of the study is to suggest a convenient way to classify the position of the impacted third molar relative to mandibular canal and to suggest indication for the use of each surgical approach for mandibular third molar extraction. Study reveals new surgical classification system for treatment planning in all types of third molar extraction.

- Oladimeji.A.Akadiri, Ambrose E .Obiechina; Assessment Of Difficulty In Third Molar Surgery - A Systematic Review ; JOMS/2009/67/771-774:

Aim of this review was to identify the most important variables that determines surgical difficulty of impacted third molar extraction. Study states that Surgeons experience and procedure type are the most important operative variables.

- Fabio Richardo Loureiro Sato,Luciana Asprino,Denis Emanuel Silva ; Short-term Outcome Of Postoperative Patient Recovery Perception After Surgical Removal Of Third Molar ; JOMS/2009/67/1083-1091:

The aim of the study was to depict surgical difficulties related to third molar removal with symptoms and signs presented postoperatively by patients, identify the most frequent occurrences and postoperative complication to present or lessen their intensity. Results showed negative effects on quality of daily activities for which all patients should be informed for better professional -patient relationship. 
6.KingKim,PardeepBrar,JesseJakubowski,StevenKaltman,EustorgioLopez; Use Of Corticosteroids And Nonsteroidal Anti-inflammatory Medication For The Management Of Pain And Inflammation After Third Molar Surgery ; OODO/2009/107/630-640:

Article review and addresses the use of NSAIDS \& corticosteroids after third molar surgery. Use of Narcotic Analgesics, NSAIDS, corticosteroids and combination of these have role in postoperative management of pain and swelling within this group of patients.

7.Michael.R.Markiewicz,Mark.F.Brady,Eric.L.Ding,Thomas.B.Dodson; Corticosteroids Reduce Post-Operative Morbidity After Third Molar Surgery : A Systematic Review and Meta-Analysis ; JOMS/2008/1882:

The purpose of this study was to apply metanalytical methods to measure the effects of corticosteroids on edema, tissues and pain at early and late postoperative periods after third molar Extraction. Results were suggestive of mild to moderate effects on reducing inflammatory symptoms upto 7 days post surgery following preoperative administration of corticosteroids.

8. Nerdy casap,Michael alterman,Guy Sharon:The effect of informed consent on stress levels associated with extraction of impacted mandibular third molars:JOMS/2008/66/878-881:

Study evaluated the effects of informed consent on stress levels associated with removal of impacted mandibular third molar. Results showed that over detailed listing and disclosure before extraction of impacted mandibular third molar can increase patient's Physiological parameters.

9. Lucia lago,Marcio diniz,Carmen senra:Relationship between surgical difficulty and postoperative pain in lower third molar extractions:JOMS/2007/65/979-983:

Article investigates the influence of surgical difficulty on postoperative pain after extraction of mandibular third molars, Results concluded by stating that pain after extraction of mandibular third molar increases with increased surgical difficulty and duration of intervention.

10. Haeman noori, David I, Daniel shugars: Third molar root development and recovery from third molar surgery: JOMS/2007/65/680-685:

Study was conducted to determine if completeness of roof formation of mandibular third molars prior to removal, affected clinical and health related quality of life recovery. Study results suggested that incomplete lower third molar root formation presurgery may not be predictor of clinical and health related quality of life recovery. Rather other factors like clinical, demographic, health indicators should influence surgeon's decision.

11. Leslie .R, Thomas.b: Does prophylactic administration of systemic antibiotics prevent postoperative inflammatory complication after third molar surgery: JOMS/2007/65/177-185:

Purpose of the study was to estimate and compare the frequency of inflammatory complication after third molar surgery in subjects receiving intravenous prophylactic antibiotic or saline placebo, suggested that use of intravenous antibiotics administered prophylactically decrease the frequency of surgical site infection.

12. Giovanni .B, Carlo maiorana, Luca creminelli: Assessing postoperative discomfort after third molar surgery: A prospective study:

JOMS/2007/65/901-917:

Purpose of this study was to identify risk factors for severe discomfort after mandibular third molar surgery and to assess validity of postoperative symptom severity scale. PossE Scale resulted in a valid and responsive measure of the severity of symptoms after surgical removal of third molar and reflected clinical severity of postoperative discomfort.

13. Givanni .Carlo maiorana, Roco alberto:Effect of submucosal injection of dexamethasone on postoperative discomfort after third molar surgery; A prospective study:JOMS/2007/65/2218-2226:

Study evaluated the effect of submucosal administration of dexamethasone sodium phosphate on discomfort after mandibular third molar surgery. Parenteral use of dexamethasone $4 \mathrm{mg}$ given as intraoral injection at the time of surgery is effective in prevention of postoperative edema. Increasing the dose to $8 \mathrm{mg}$ provides no further benefits. 
14. Colorado.B,Valamseda .C, Gay escoda:Quality of life following lower third molar removal:JOMS/2006/35/343-37:

Objective of this study was to evaluate the quality of life and degree of satisfaction among adult outpatients after surgical extraction of a lower third molar under local anesthesia, to assess the impact of thorough explanation of anticipated postoperative course on their pain and daily activities. Results indicated negative effects on quality of life and environment, particularly first three days after extraction.

15. Torres.L,Gutierrez.P, and Infante.C:Randomized,double-blind study on effectiveness of intraalveolar chlorhexidine gel in reducing the incidence of alveolar osteitis in mandibular third molar surgery:JOMS/2006/35/398-351:

Article evaluated chlorhexidine mouthwash gel as a prophylactic agent for post extraction alveolar osteitis, recently bioadhesive gel form of chlorhexidine was introduced to deliver active substance.Intra alveolar position of this gel allows more direct and prolong action of chlorhexidine. Results were suggestive of reduced incidence of alveolar Osteitis following removal of impacted third molars.

16. Shaul lin, Liran Levin,Omri emodi:Etodolac versus dexamethasone effect in reduction of postoperative symptoms following surgical endodontic treatment: A double -blind study:0000/2006/010/814-817:

Article analyzed the effect of etodolac versus dexamethasone in reducing postoperative pain in patients who had surgical endodontic treatment. Results indicated that both etodolac and dexamethasone had a significant effect on reducing postoperative pain when compared with placebo in patient who had surgical endodontic treatment.

17. A markovic,Lj todorvic:Effectiveness of dexamethasone and low power laser in minimizing oedema after third molar surgery:A clinical trial:JOMS/2007/36/226- 229:

Aim of this study was to compare the effectiveness of low power laser and dexamethasone after surgical removal of impacted lower third molars under local anesthesia. Low Power Laser with local use of dexamethasone resulted in statistically significant reduction of postoperative oedema in comparison to other groups. No adenine effects of the procedure or medication were observed.

\section{Donald .J,Daniel.A,Raymond.P:Proximity of lower third molar to the inferior alveolar canal as predictor of delayed recovery:JOMS/2006/64/1371-1376:}

This study was designed to test hypothesis that removal of lower third molars below the occlusal plane and in close proximity to infirm alveolar canal delays recovery after surgery as compared to lower third molars below occlusal plane yet not close to inferior alveolar canal. Results favoured the hypothesis and created prolonged health related quality outcomes of life recovery, but no significant delay in clinical recovery.

\section{T.moki,H.yamaguch,H.naito:Premedication with cyclooxygenase-2inhibitor meloxicam reduced postoperative pain in patients after oral surgery:IJOMS/2006/35/613-617:}

The efficacy of selective COX-2 inhibitor meloxicam for treatment of postoperative surgical pain was assessed in randomized control trial. VAS - Score was used to assess pain on $1^{\text {st }}, 7^{\text {th }}, 14^{\text {th }}$ Postoperative day. Results revealed COX-2 inhibitor, meloxicam $10 \mathrm{mg}$ used for premedication reduced postoperative pain compared to control in oral surgery.

20. J.vander,J.becker,J.morkel:A randomized observer blind comparison of bilateral facial icepack therapy with no ice therapy following third molar surgery:IJOMS/2005/34/281-286:

Study compared bilateral facial ice packs with no cold therapy in reducing pain, swelling and trismus during first 24 hours following third molar surgery. Ice packs were applied the 15 minutes following surgery and then continuously for next 24 hours. Results stated no difference in the two groups.

21. P.presser, V.fontanella:Analgesic efficacy of Aceclofenac after surgical extraction of impacted lower third molars: IJOMS/2006/35/518-521:

Study compared analgesic efficacy of aceclofenac in control of pain after surgical extraction of compacted third molars with its preoperative administrations. All surgeries were performed by the same surgeon by same technique. 
Results indicated statistically significant reduction of pain at 6 hours after surgery when aceclofenac was administered preoperatively.

22. F.graziani,M.tonelli:Perioperative dexamethasone reduces post-surgical sequelae of wisdom teeth removal ,A split mouth randomized double-masked clinical trial:IJOMS/2006/35/241-246:

Article studied the effect of endoalveolar and submucosal administration of dexamethasone Sodium phosphate to prevent inflammatory signals after surgical removal of lower third molars. Facial Edema tissues and pain perception were evaluated at $2^{\text {nd }}$ and $7^{\text {th }}$ post-operative day. Study revealed treatment and Osteotomy time had positive significance in postoperative trismus and edema. Both submucusal and endo alveolar administration of dexamethasome are effective in reducing postoperative sequelae on surgical removal of lower third molar.

23. Paul tiwana,susan .p,Robert marciani:The impact of intravenous corticosteroids with third molar surgeryin patiens at high risk for delayed health -related quality of life and clinical recovery:JOMS/2005/63/55-62:

Study compared recovery for clinical and health related quality of life outcomes after third molar surgery in patients predicted to be at risk for delayed recovery treated with or without intravenous corticosteroids at surgery. Administration of IV corticosteroids before third molar surgery had limited but beneficial outcomes on Health related quality of life outcomes as concluded by study.

24. Mckinzie.S,Daniel.S,Raymond white: Pain medication as an indicator of interference with lifestyle and oral function during recovery after third molar surgery:JOMS/2005/63/1130-1137:

Study was designed to assess the impact of taking pain medication as a more comprehensive indicator of perceived pain on extent of interference with life style and oral function during recovery after third molar surgery. Study indicated that patient's choice to take pain medication appears to be better indicator of a patients perceived pain and the impact of that pain on recovery than numeric pain scales.

25. Andrew.T,Daniel.S,Raymond white:The impact of delayed clinical healing after third molar surgery on health related quality of life outcomes:JOMS/2005/63/929-935:

Article examined the impact of delayed clinical healing after third molar surgery on health related quality of life recovery. Delayed clinical healing after third molar surgery significantly increased the prevalence of delayed recovery of life style, oral functions, late symptoms and pain.

26. D.pasqualini,N.cocero,Acaste lla:Primary and secondary closure of the surgical wound after removal of mandibular third molars:A comparative study:IJOMS/2005/34/52-57:

This study compared primary and secondary closure techniques after removal of impacted third molars in terms of post-operative pain and swelling. Result stated that pain and swelling were less severe with secondary healing than primary healing.

27. Srinivas.M,Thomas.B:Estimating third molar extraction difficulty:A comparison of subjective and objective factors;JOMS/2005/63/427-434:

The purpose of this study was to compare and contrast subjective and objective assessments of variables associated with third molar extraction difficulty.Variables compared were gender,arch location, winter classification, tooth morphology, type of procedure and surgical experience. Article concluded with stating that there was large positive conclusion between variables that surgeon considered most important is determining third molar Extraction difficulty.

28. Michael.S,Thomas .B:Panoramic radiographic findings as predictors of inferior alveolar nerve exposure following third molar extraction:JOMS/2005/63/3-7:

The aim of this study was to estimate the sensitivity and specificity of panoramic radiographic finding in relation to inferior alveolar nerve exposure after mandibular third molar extraction. Radiographic findings: darkening of root, narrowing of root, interruption of white line and diversion of canal were statistically associated with IAN exposure following lower third molar Extraction.

29. Babatunde.B,Jelili Adisa:Effects of coadministered dexamethasone and diclofenac on pain,swelling and trismus following third molar surgery: Head and face Medicine/2005/1/11: 
Aim of the study was to compare the effect of coadministered dexamethasone and diclofenac potassium with diclofenac $\mathrm{K}$ alone on postoperative pain, swelling and trismus after surgical extraction of lower third molars. This study illustrates enhanced effects of coadiministered dexamethasone and diclofenac-k on short term postoperative pain, swelling and tissues, compared to diclofenac potassium alone in third molar surgery.

30. H.chang,Jlee,J yang:Periodontal healing after mandibular third molar surgery-A comparison of distolingual alveolectomy and tooth division techniques:IJOMS/2004/3/32-37:

Purpose of this study was to compare the periodontal healing of mandibular second molars after the removal of impacted mandibular third molars using distolingual alveolectomy and tooth division techniques, Attachment level, periodontal pocket depth and bone healing distal to second molar were evaluated at $7^{\text {th }}$ day 10 months and 6 months after surgery. Result showed improved periodontal healing and bone healing in distolingual alveolectomy technique.

31. Hidemichi .Y,Masayuki.S:Clinical postoperative findings after removal of impacted mandibular third molars-prediction of postoperative facial swelling and pain based on preoperative variables:BJOMS/2004/42/209-214:

Paper investigates relationship between preoperative findings and short term outcome in third molar surgery. Study revealed that short term outcomes of third molar operation differ depending in patient's age, sex and preoperative index of difficulty.

32. S.ong,A.seymor,G.chen:Preoperative ketorolac has a preemptive effect for postoperative third molar surgical pain:IJOMS/2004/33/771-776:

This study evaluates efficacy of preemptive Ketorolac in a crossover designs in patients undergoing bilateral mandibular third molar surgery. Throughout the study period patient reported significantly lower pain intensity scores in Ketorolac pretreated sites. Study concluded with stating pretreatment intravenous Ketorolac has preemptive effect for analgesia following third molar surgery with extended analgesia for approximately 2 hours.

33. S.ong,L.tang:Preoperative intravenous tramadol versus ketorolac for preventing postoperative pain after third molar surgery:IJOMS/2004/33/274-278:

Objective of this study was to compare the analgesic efficacy of a single dose of preoperative intravenous tramodal versus Ketorolac in preventing pain after third molar surgery. Patient reported significantly lower pain intensity scores in Ketoralac versus tramadol group. Study resulted in prevention of postoperative dental pain after third molar surgery with use of 30mg Ketorolac more effectively than tramadol $50 \mathrm{mg}$.

34. Srinivas.M,Thomas.D:Risk factors for third molar extraction difficulty:JOMS/2004/62/1363-1371:

Purpose of this study was to measure the difficulty of third molar extraction and identify demographic, anatomic and operative variables associated with extraction difficulty. Study model revealed that the difficulty of third molar extraction is governed primarily by anatomic and operative factors with minimal influence from demographic factors.

35. David halmos,Edward eliis-III:Mandibular third molars and angle fractures:JOMS/2004/62/10761081:

Study evaluated association between mandibular third molar status/position and risk for angle fracture. Variables included presence or absence of third mo or absence of third molar, pell and Gregory's system. The presence of mandibular third molars was associated with 2.8 fold increased risk of angle fractures. Notably deep impaction were not associated with increased risk of fracture.

36. Anthony pogrel,Kim.E:Lingual flap retraction for third molar removal:JOMS/2004/62/1125-1130:

This study reports a trial of technique of deliberately exposing lingual tissues to retract lingually before tooth removal, the traditional approach is however buccal approach avoiding exposure to lingual side. This prospective study revealed that lingual retraction for third molar removal improves access to surgical site and simplify the removal, and there were no cones of permanent lingual never injury associated with it.

37. Andrew tay,Wee ser :Effect of exposed inferior alveolar neurovascular bundle during surgical removal of impacted lower third molars:JOMS/2004/62/592-600: 
Study determines the incidence of inferior alveolar nerve paresthesia in patients with exposed inferior alveolar bundles seen intraoperatively. Patients were reviewed 1 week after surgery and evaluated subjectively and objectively to determine incidence of paresthesia when inferior alveolar bundle was exposed. Result showed $20 \%$ risk of paresthesia with $70 \%$ chances of recovery by 1 year from surgery.

38. Ann wenzel,Jens .K,Hanne.H:Mandibular third molar removal-risk indicators for extended time,postoperative pain and complication: 0000/2004/97/438-446:

Aim of the study was to identify risk indicators for extended operation time and postoperative complication of the removal of mandibular third molar. Older patients were at high risk for extended operation time than younger patients. Visible Inferior alveolar nerve during operation was repeatedly found to be a single highest risk indication.

39. J paweljick,M.cohen, $R$ willers:A comparison of conventional panoramic radiograph with volumetric computed tomography images in the preoperative assessment of impacted mandibular third molars:JOMS/2002/60/979-984:

Study evaluated geometric, topographic and anatomic reliability of volumetric computed tomography images by comparing conventional panoramic radiographs with reconstructed VCT panoramic and paraxial images before performing third molar surgery. Result showed VCT paraxial images more significant in perception of mandibular nerve than conventional panoramic radiography. However conventional panoramic radiographs were better than VCT reconstructed panoramic images in viewing mandibular nerve.

40. H.yuasa,T kawai,M suigura:Classification of surgical difficulty in extracting impacted third molars:IJOMS/2002/40/26-31:

Study attempted to analyse preoperative factors like depth, ramus relationship, width of root or continuation of these factors that complicate surgical removal of impacted mandibular third molars. The new index had an relative risk of 62.3, sensitivity of 0.85 and specificity of 0.92 as compared to Pederson's index.

41. John $R$ zuniga:Guidelines for anxiety control and pain management in oral and maxillofacial surgery:JOMS/2000/58/4-7:

Articles, reviews, guidelines and policies for the use of sedatives and anesthetics in dental and hospital settings including ADA, AADMS,APS, AAP and AAPD, and pain management guidelines by WHO, AHCPR. Based on guidelines it is possible to outline a generally accepted set of procedures that should be used in control of postoperative pain and anxiety in oral and maxillofacial surgery.

42. A Garcia,F gude:Pell-gregory classification is unreliable as a predictor of difficulty in extracting lower third molars: BJOMS/2000/38/585-587:

Study presented surgical extraction of impacted mandibular third molar, all extracted by same surgeon.Classified accordingly to pell - Gregory scales of position A- C and Ascending ramus I - III, with extraction being subsequently noted "easy" or "difficult". Both Pell and Gregory position and class in the study indicated little value in predicting a difficult extraction.

43. David Shaffer, Marion frank:Gustatory function after third molar extraction:000/1999/87/419-428:

Purpose of this study was to determine the serenity and time course of taste changes after extraction of all 4 third molars, taste function in all patients were measured before surgery, 1 month and 6 months after surgery which include intensities and taste quality of various solution with an additional localized test. Results indicated that gustatory deficits occur after third molar extraction, persist for as long as 6 months after surgery and appears to be associated with depth of impaction.

44. Emin,Ferda\&Okan:Determination of the Anti-Inflammatory effects of Methylprednisolone on the sequelae of third molar surgery.JOMS/1999/57/1201-1206:

Study evaluates anti inflammatory and adrenal suppressive side effect of methylprednisolone sodium succinate on postoperative sequale of third molar surgery. Each patient was given $125 \mathrm{mg}$ of methyl prednisolone IV before surgery on one side and placebo before surgery on other side. Facial edema was determined using USG and CTexamination, tissues evaluated using interincisal distance and pain using number of analgesic tablets used. HPAaxis tested using plasma cortisol levels, ACTH before and after methyl prednisolone administration. Results favoured the use of corticosteroids in third molar surgery if no contraindication existed. 
45. Emin,esen,Ferda,teser:Determination of anti-inflammatory effects of methylprednisolone on the sequale after third molar surgery:JOMS/1999/57/1206-1208:

Study advocates the benefits of using corticosteroids to reduce postoperative edema, pain and tissues associated with removal of impacted third molar. However it also necessitates that well designed clinical trials are needed to determine the dose-response relationship for corticosteroids, and also to determine the use of USG and CT-Scan for evaluation of clinical data during the procedure.

s46. Seymore.A,J.frame:The comparative efficacy of aceclofenac and ibuprofen in pot operative pain after third molar surgery. BJOMS/1998/36/375-379:

Aim of the study was to compare the efficacy of single doses of aceclofenac $150 \mathrm{mg}$ and Ibuprofen $400 \mathrm{mg}$ in postoperative pain after third molar surgery. Pain intensity and relief were measured on VAS over period of 6 hours. Study resulted in providing significant pain relief in early post-operative period following single dose ibuprofen 400mg when compared to single dose aceclofenac $150 \mathrm{mg}$.

47. Sutas .S,Verasak.P:Mandibular third molar surgery with primary closure and tube drain:IJOMS/1997/26/187-190:

The insertion of small surgical tube drain with primary wound closure was compared to a simple primary wound closure after removal of impacted third molars. Variables like significant wide month opening, no difference in pain and less facial edema were present in drain groups as compared to non-drains group.

48. A Garcia,F gude:Trismus and pain after removal of impacted lower third molars: JOMS/1997/55/12231226:

Study evaluated tissues and pain after removal of impacted lower third molars and investigated that these responses were related to difficulty of surgery. Difficulty of surgery was evaluated on modified panant scale and trismus evaluated using interincisal distance and pain on basis of analgesics used. Results indicated that trismus severity did not relate to difficulty of surgery and pain disclosed between day 1 and 5 post surgery.

49. T.lizuka,Sandro.T:Mandibular fractures following third molar extraction:IJOMS/1997/26/338-343:

This article analysed patients with mandibular fractures following third molar extraction. Clinical and radiographic data relating to there patients were analysed. Clinically age of the patient, with $30-40$ years were considered to be risk group fracture type was regardless of degree of impaction and tooth position.

50. D Thomas,M hill:An audit of antibiotic prescribing in third molar surgery:BJOMS/1997/35/126-128: Article is an audit of antibiotic presenting practice in third molar surgery. Use of antibiotics as a prophylactic measure against infection is widespread following removal of impacted third molars. However the advantage of using such prophylaxis appear to be marginal and there is little evidence to support the use of second and third generation antibiotics in routine prophylaxis:

51. Tarel.L,Hussain A: Clinical evaluation of dexamethasone Vs methylprednisolone for reducing inflammatory sequelae following third molar surgery: Saudi dental Journal 1996/8-1/13-18:

Article studies the efficacy of submucosal local infiltration of dexamethasone Vs methyl prednisolone in reducing postoperative pain, trismus and swelling after surgical removal of impacted mandibular third molars. Results showed that duration of facial swelling was same in both groups, dexamethasone showed less marked pain than counter part. Trismus was significantly less in methylprednisolone group as compared to dexamethasone. A 125 $\mathrm{mg}$ methylprednisolone was significantly more effective than $4 \mathrm{mg}$ dexamethasone in reducing postoperative sequelae following third molar surgery.

52. Jose R,Paul Edward,Clinical comparative study of the effectiveness of two dosages of dexamethasone to control postoperative swelling,trismus and pain after the surgical extraction of mandibular impacted third molars:Med Oral patol Oral Cir Buccal|2008\Feb13\E 129-132

Article evaluates the effect of two different dosages of dexamethasone in postoperative sequale following third molar surgery. Study resulted in stating that increasing the dose to $8 \mathrm{mg}$ more effectively controlled the postoperative sequelae than $4 \mathrm{mg}$.However, it had no effect on pain control.

53. K boonsiriseth, $N$ Srin tawat:Comparative study of the effect of dexamethasone injection and consumption in lower third molar surgery:Ijoms $\backslash 2012 \backslash 41 \backslash 244-247$ 
This study was conducted to evaluate the effect of intramuscular injection and consumption of 8mg dexamethasone in lower third molar surgery.There was no significant difference in the two groups .The results concluded that IM injection or consumption of dexamethasone can be used to control postoperative sequale.

54. V lopes, $M$ harris:Third molar surgery-An audit of the indication for postoperative complaints and patients satisfaction:Bjoms 1 1995 $\backslash 33 \backslash 33-35$

This study was a prospective investigation of patient undergoing third molar sugery .Data related to indication for surgery and quality of care was collected .Study supported clear indication for surgery thereby reducing socioeconomic and health related queries.

55. Dandona et.al Effect of dexamethasone on reactive oxygen species generation by leukocytes and plasma interleukin-10 concentration:A pharmacodynamics study:Clinical pharmacology \&theurapeutics-volume 66,number 1

Study reviews the concept of inhibition of reactive oxygen species generation by leukocytes by the use of hydrocortisone .Dexamethasone was investigated at a dose of $4 \mathrm{mg}$ which is equivalent to $100 \mathrm{mg}$ hydrocortisone. Study revealed that dexamethasone exerts its immunosuppressive and anti-inflammatory effects by inhibiting reactive oxygen species by leukocytes and by increasing the concentration of IL-10.

56. Wajeed et.al Effect of submucosal and intramuscular Dexamethasone on postoperative sequelae after third molar surgery:comparative study

This study compared the effects of dexamethasone given submucosally and intramuscularly on postoperative complication after removal of impacted lower third molars .Overall the study stated that submucosal dexamethasone is an effective alternative to dexamethasone given systemically on control of postoperative sequale following third molar surgery.

\section{Aims \& Objectives:-}

1. To compare the efficency of $4 \mathrm{mg}$ Dexamethasone given locally at the operated site and systemically in surgical extractions of similarly impacted mandibular third molars .

2. To evaluate the postoperative complications like pain, swelling and mouth opening following the administration of Dexamethasone.

\section{Material and Method:-}

\section{Source of data:}

Patient reporting to Department of oral and maxillofacial surgery, Vishnu dental college ,Bhimavaram .

\section{Method of study:}

A sample of 30 patients with similar bilaterally impacted mandibular third molars.

\section{Inclusion criteria:}

a.Patients who are healthy and periodontally sound.

b.Patients in the age group of 16-35 years.

C.Patients with similar bilaterally impacted mandibular third molars classified under Pell \& Gregory's classification as class-II,III and position A,B,C.

d.All the patient would be informed about the study and there consent would be taken to participate in the study.

\section{Exclusion criteria:-}

- Acute or chronic infection

- Ocular herpes simplex

- Primary glaucoma

- Acute psychosis

- Renal insufficiency

- Hypertension 
- Osteoporosis

- Diabetes mellitus

- Cushing syndrome

- Pregnancy and lactation

1. Patients will be operated bilaterally with an interval of 4 weeks between the sides.

2. With one surgical site receiving local administration of steroid at the operating site designated as group-A and the other systemic administration into the cephalic vein as group-B of Dexamethasone $4 \mathrm{mg}$.

3. Local administration of the drug is given in the raised mucoperiosteal flap before ostectomy.

4. Systemic administration of the drug in the cephalic vein before the procedure.

5. All the surgical procedures are done by a single operator.

\section{Data collection:-}

1. Mouth opening-By measuring interincisal distance.

2. Swelling-Tape measuring method(from the lower most part of ear lobule to midline of mandible)

3. Pain-scored using VAS scale.

The data are collected preoperatively and postoperatively on $2^{\text {nd }}$ and $7^{\text {th }}$ day. All the data obtained are subjected to statistical analysis.

\section{Pharmacology Of Dexamethasone:-}

During 1957 Arth et al synthesized a new family of steroid compounds containing in common, a methyl group at the sixteenth carbon position of the steroid nucleus. One of these compounds was dexamethasone.

Dexamethasone (9 fluoro 16 methylprednisolone) is a white odorless compound which is slightly soluble in water $(0.1 \mathrm{mg} / \mathrm{cm})$. It has a melting point of $240^{\circ} \mathrm{C}$ to $260^{\circ} \mathrm{C}$. It is a synthetic analogue of prednisolone in which a methyl group has been added at the carbon 16 position and fluorine atom at carbon 9 position. It has been known that the addition of fluorine at carbon 9 position greatly enhances the anti-inflammatory activity of the resulting compound.

\section{Structure of dexamethasone:-}

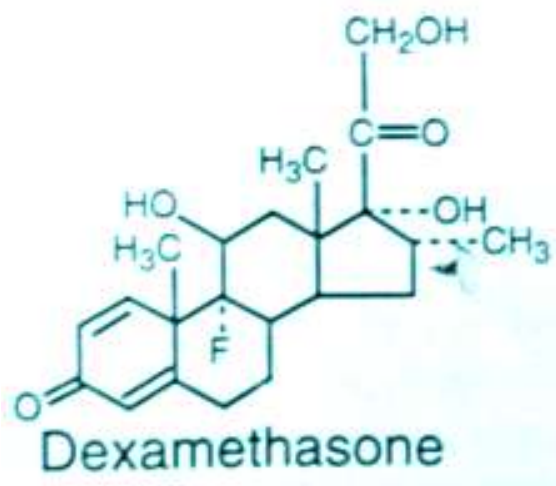

\section{Control of cortisol secretion:-}

The control of cortisol secretion is through the hypothalamic-pituitary-adrenal (HPA) axis. The first step in the activation of this axis is neural excitation of the hypothalamus to release a peptide called corticotrophin releasing factor (CRF) which travels to the pituitary by the portal circulation in the pituitary stalk. CRF in turn stimulates the release of adrenocorticotrophic hormone (ACTH) from the anterior pituitary gland. ACTH has an influence on the function of all the adrenal steroids, although its primary action is to stimulate the formation of the glucocorticoids (principally cortisol). The degree of activity of the HPA axis has three main physiological determinants:

- The circadian rhythm

- A negative feed back mechanism

- Responsiveness to stress 
The circadian rhythm: The rate of secretion of ACTH (and hence of cortisol) is not constant during the day. The maximum blood level is reached at about 8 am and the minimum at about midnight. The mechanism controlling this circardian rhythm is unknown.

A negative feed back mechanism: The concentration of free plasma cortisol influences the secretion of ACTH in such a way that an increase in the level of free plasma cortisol leads to a reduction in the secretion of ACTH and vice versa a negative feedback mechanism.

Stress: There is a great increase in activity of the HPA axis in response to stress. Such stress can arise from several causes including emotional status (excitement, fear) neurological status (pain), altered metabolic status (pyrexia hypoglycemia), surgical trauma and anesthesia.

\section{Hypothalamic-pituitary-adrenal axis:-}

The hypothalamic-pituitary-adrenal axis (HPA axis) refers to a complex set of direct influences and feedback interactions between: the Hypothalamus, a hollow, funnel-shaped part of the brain; the Pituitary gland, a pea-shaped structure located below the hypothalamus; and the Adrenal or suprarenal gland, a small, paired, pyramidal organ located at the top of each kidney. The fine, homeostatic interactions between these three organs constitute the HPA axis, a major part of the neuroendocrine system that controls reactions to stress and regulates various body processes including digestion, the immune system, mood and sexuality, and energy usage. Species from humans to the most ancient organisms share components of the HPA axis. It is the mechanism for a set of interactions among glands, hormones and parts of the mid-brain that mediate a general adaptation syndrome.

\section{Mechanism of action of anti-inflammatory effect:-}

The anti-inflammatory effects depend upon the direct local action of the steroids. The most important factor in the anti-inflammatory action of dexamethasone (glucocorticoids in general) can be attributable to their ability to inhibit the recruitment of neutrophils and monocyte/ macrophages in the affected area. Low concentrations of steroids inhibit the formation of plasminogen activation by neutrophils. There is also substantial evidence that dexamethasone inhibits phospholipase A2 and thereby diminishes the release of arachidonic acid from phospholipids. This decreases the formation of prostaglandin, endoperoxides and thromboxane which plays an important role in chemotaxis and inflammation. The other actions are:

- Carbohydrate and protein metabolism.

- Lipid metabolism

- Electrolyte and water balance

- Cardiovascular

- Other effects on - Blood pressure

Central nervous system

Skeleton

Hormonal integration

\section{Carbohydrate, fat and protein metabolism:-}

There is enhancement of gluconeogenesis and antagonism to the action of insulin. Dexamethasone promotes the catabolism of proteins but also to inhibit their anabolism. This leads to negative nitrogen balance. But it is not seen with short term low dose therapy and reverse back to normal as soon as the drug is withdrawn.

\section{Water and salt metabolism:-}

Dexamethasone has less effect on water and salt metabolism. Low dose dexamethasone therapy produces no increase in retention of sodium and excretion of potassium ions.

\section{Other actions:-}

Dexamethasone aid shift of body fluids from the intracellular to the interstitial space, making the fluid available to support the cardiovascular system at the times of blood loss.

\section{Risks and contraindications:-}

When properly used Dexamethasone is a valuable assert in the treatment of inflammation. Short term administration of corticosteroids single dose $4 \mathrm{mg}$ to $8 \mathrm{mg}$ is relatively safe. The following are risks seen in prolonged doses of corticosteroids. 
- $\quad$ Signs and symptoms of underlying diseased states may be suppressed and therefore go undiscovered.

- Development of Cushing's syndrome and hypothalamic pituitary adrenal suppression occurs after one month of daily administration of $20 \mathrm{mg}$ of hydrocortisone or its equivalent doses of Dexamethasone.

- $\quad$ Other adverse effects are :

- posterior sub capsular cataracts

- glaucoma

- hypertension

- myopathy

- osteoporosis

- alteration in mood or personality psychosis

- thin fragile skin

- impaired wound healing

- alopecia

Absolute contraindications:

- Active infection or incompletely healed tuberculosis

- Ocular herpes simplex

- Primary glaucoma

- Acute psychosis

Relative contraindications:

- Active or latent peptic ulcer

- Cushing's syndrome

- Diverticulitis -recent intestinal anastomosis

- Renal insufficiency

- Hypertension

- Osteoporosis

- Diabetes mellitus

- Myasthenia gravis.

- Psychotic tendencies.

- Acute or chronic infections

\section{Absorption fate and excretion:-}

Dexamethasone is rapidly and completely adsorbed from the gastrointestinal tract. Adsorption from intramuscular site is much slower and hence the effect lasts much longer.

\section{Interactions with other drugs:-}

Dexamethasone enhances the renal clearance of salicylates. Abrupt cessation of the former in a patient who is receiving both drugs may precipitate salicylate toxicity. On the other hand drugs such as barbiturates, phenytoin and rifampicin increase the degradation of glucocorticoids by hepatic microsomal enzyme induction.

\section{Preparations:-}

Non proprietary name: Dexamethasone

Proprietary name: Decadron, Dexone, Hexadrol

Relative potency -25

Usual adult dose: $0.75-9.0 \mathrm{mg} /$ day

Route of administration: oral

Tablets: $0.25,0.50,0.75,1,1.5,2,4 \& 6 \mathrm{mg}$

\section{Results:-}

Table 1:

\begin{tabular}{|l|l|l|l|l|l|l|}
\hline $\begin{array}{l}\text { MOUTH OPENING } \\
\text { (LOCAL) }\end{array}$ & MIN & MAX & MEAN & SD & $\begin{array}{l}\text { F- } \\
\text { VALUE }\end{array}$ & P VALUE \\
\hline $\begin{array}{l}\text { PREOPERATIVE } \\
\text { VALUES }\end{array}$ & 35.00 & 56.00 & 44.53 & 5.37 & 12.57 & $\begin{array}{l}<0.001 \\
\text { Significant }\end{array}$ \\
\hline
\end{tabular}




\begin{tabular}{|l|l|l|l|l|l|l|}
\hline 2nd POST OP DAY & 22.00 & 52.00 & 37.13 & 6.93 & & \\
\cline { 1 - 5 } 7th POST OP DAY & 34.00 & 54.00 & 42.13 & 5.02 & & \\
\hline
\end{tabular}

Statistical Analysis: ANOVA one way test. Statistically significant if $\mathrm{P}<0.05$

Table 2:

\begin{tabular}{|c|c|c|c|c|}
\hline MOUTH OPENING (LOCAL) & MEAN & SD & Difference & $\mathrm{P}$ value \\
\hline PREOPERATIVE VALUES & 44.53 & 5.37 & \multirow[t]{2}{*}{$7.40 \pm 1.56$} & \multirow{2}{*}{$\begin{array}{l}<0.001 \\
\text { Significant }\end{array}$} \\
\hline 2nd POST OP DAY & 37.13 & 6.93 & & \\
\hline PREOPERATIVE VALUES & 44.53 & 5.37 & \multirow[t]{2}{*}{$2.40 \pm 0.35$} & \multirow{2}{*}{$\begin{array}{l}0.254 \\
\text { Not significant }\end{array}$} \\
\hline 7th POST OP DAY & 42.13 & 5.02 & & \\
\hline 2nd POST OP DAY & 37.13 & 6.93 & \multirow[t]{2}{*}{$5.00 \pm 1.91$} & \multirow{2}{*}{$\begin{array}{l}0.004 \\
\text { Significant }\end{array}$} \\
\hline 7th POST OP DAY & 42.13 & 5.02 & & \\
\hline
\end{tabular}

Statistical Analysis: Post Hoc Tukey HSD test. Statistically significant if $\mathrm{P}<0.05$

Comparison of preoperative mouth opening in locally administred dexamethasone to $2^{\text {nd }} \& 7^{\text {th }}$ postoperative day(Table I, Table II,Chart I):-

a.Overall there was statistically significant difference in the values of preoperative mouth opening when compared to 2 day and 7 day postoperative day

b. Preoperative and $2^{\text {nd }}$ and $7^{\text {th }}$ day values had a SD of 5.37,6.93 and 5.02 respectively with significant p-value.

Table 3:

\begin{tabular}{|c|c|c|c|c|c|c|}
\hline $\begin{array}{ll}\text { MOUTH } & \text { OPENING } \\
\text { (SYSTEMIC) }\end{array}$ & MIN & MAX & MEAN & SD & $\begin{array}{l}\text { F- } \\
\text { VALUE }\end{array}$ & P VALUE \\
\hline $\begin{array}{l}\text { PREOPERATIVE } \\
\text { VALUES }\end{array}$ & 35.00 & 56.00 & 44.53 & 5.37 & \multirow[t]{3}{*}{26.73} & \multirow[t]{3}{*}{$\begin{array}{l}<0.001 \\
\text { Significant }\end{array}$} \\
\hline 2nd POST OP DAY & 23.00 & 49.00 & 33.13 & 6.77 & & \\
\hline 7th POST OP DAY & 30.00 & 53.00 & 39.77 & 5.98 & & \\
\hline
\end{tabular}

Statistical Analysis: ANOVA one way test. Statistically significant if $\mathrm{P}<0.05$

Table 4:

\begin{tabular}{|c|c|c|c|c|}
\hline MOUTH OPENING (SYSTEMIC) & MEAN & SD & Difference & $\mathrm{P}$-value \\
\hline PREOPERATIVE VALUES & 44.53 & 5.37 & \multirow[t]{2}{*}{$11.40 \pm 1.40$} & \multirow{2}{*}{$\begin{array}{l}<0.001 \\
\text { Significant }\end{array}$} \\
\hline 2nd POST OP DAY & 33.13 & 6.77 & & \\
\hline PREOPERATIVE VALUES & 44.53 & 5.37 & \multirow[t]{2}{*}{$4.76 \pm 0.61$} & \multirow{2}{*}{$\begin{array}{l}0.009 \\
\text { Significant }\end{array}$} \\
\hline 7th POST OP DAY & 39.77 & 5.98 & & \\
\hline 2nd POST OP DAY & 33.13 & 6.77 & \multirow[t]{2}{*}{$6.64 \pm 0.79$} & \multirow{2}{*}{$\begin{array}{l}<0.001 \\
\text { Significant }\end{array}$} \\
\hline 7th POST OP DAY & 39.77 & 5.98 & & \\
\hline
\end{tabular}

Statistical Analysis: Post Hoc Tukey HSD test. Statistically significant if $\mathrm{P}<0.05$

Comparison of preoperative, 2 day and 7 day mouth opening in systemically administered dexamethasone(Table III, Table IV,Chart II).

a. When mouth opening was compared between preoperative, 2 day and 7 day measurements, a statistically significant difference was found between these periods in this group with p-values of $<0.001$ in each of these groups.

b.The SD was $5.37,6.77,5.98$ preoperative, 2 day and $7^{\text {th }}$ day respectively.

Table 5:

\begin{tabular}{|l|l|l|l|l|l|l|}
\hline SWELLING (LOCAL) & MIN & MAX & MEAN & SD & $\begin{array}{l}\text { F- } \\
\text { VALUE }\end{array}$ & P VALUE \\
\hline PREOPERATIVE VALUES & 125.00 & 160.00 & 137.40 & 9.31 & 3.195 & 0.046 \\
\hline
\end{tabular}




\begin{tabular}{|l|l|l|l|l|l|l|}
\hline 2nd POST OP DAY & 130.00 & 165.00 & 143.13 & 8.97 & & \multirow{2}{*}{ Significant } \\
\hline 7th POST OP DAY & 125.00 & 160.00 & 139.00 & 8.91 & & \\
\hline
\end{tabular}

Statistical Analysis: ANOVA one way test. Statistically significant if $\mathrm{P}<0.05$

Table 6:

\begin{tabular}{|c|c|c|c|c|}
\hline SWELLING (LOCAL) & MEAN & SD & Difference & $\mathrm{P}$ value \\
\hline PREOPERATIVE VALUES & 137.40 & 9.31 & \multirow[t]{2}{*}{$5.73 \pm 0.34$} & \multirow{2}{*}{$\begin{array}{l}0.043 \\
\text { Significant }\end{array}$} \\
\hline 2nd POST OP DAY & 143.13 & 8.97 & & \\
\hline PREOPERATIVE VALUES & 137.40 & 9.31 & \multirow[t]{2}{*}{$1.60 \pm 0.40$} & \multirow{2}{*}{$\begin{array}{l}0.774 \\
\text { Not significant }\end{array}$} \\
\hline 7th POST OP DAY & 139.00 & 8.91 & & \\
\hline 2nd POST OP DAY & 14313 & 897 & \multirow{2}{*}{$4.13 \pm 0.06$} & \multirow{2}{*}{$\begin{array}{l}0.187 \\
\text { Not significant }\end{array}$} \\
\hline 7th POST OP DAY & 139.00 & 8.91 & & \\
\hline
\end{tabular}

Statistical Analysis: Post Hoc Tukey HSD test. Statistically significant if $\mathrm{P}<0.05$

Comparison of preoperative, 2 day and 7 day with respect to swelling in local group(Table V \& VI, Chart IV).

- $\quad$ statistically significant difference was found in preoperative, $2^{\text {nd }}$ day and $7^{\text {th }}$ day values with respect to mouth opening with $\mathrm{p}$-value being $<0.05$.

- The SD was 9.31,8.97 and 8.91 in respect to preoperative and post operative values on $2^{\text {nd }}$ and $7^{\text {th }}$ day

Table 7:

\begin{tabular}{|l|l|l|l|l|l|l|}
\hline SWELLING (SYSTEMIC) & MIN & MAX & MEAN & SD & $\begin{array}{l}\text { F- } \\
\text { VALUE }\end{array}$ & P VALUE \\
\hline PREOPERATIVE VALUES & 125.00 & 160.00 & 137.40 & 9.31 & 6.024 & 0.004 \\
\cline { 1 - 5 } 2nd POST OP DAY & 128.00 & 168.00 & 145.57 & 9.34 & & Significant \\
\hline 7th POST OP DAY & 125.00 & 160.00 & 139.77 & 9.48 & & \\
\hline
\end{tabular}

Statistical Analysis: ANOVA one way test. Statistically significant if $\mathrm{P}<0.05$

Table 8:

\begin{tabular}{|c|c|c|c|c|}
\hline SWELLING (SYSTEMIC) & MEAN & SD & Difference & $P$ value \\
\hline PREOPERATIVE VALUES & 137.40 & 9.31 & \multirow[t]{2}{*}{$8.17 \pm 0.03$} & \multirow{2}{*}{$\begin{array}{l}0.003 \\
\text { Significant }\end{array}$} \\
\hline 2nd POST OP DAY & 145.57 & 9.34 & & \\
\hline PREOPERATIVE VALUES & 137.40 & 9.31 & \multirow{2}{*}{$2.37 \pm 0.17$} & \multirow{2}{*}{$\begin{array}{l}0.593 \\
\text { Not significant }\end{array}$} \\
\hline 7th POST OP DAY & 139.77 & 9.48 & & \\
\hline 2nd POST OP DAY & 145.57 & 9.34 & \multirow[t]{2}{*}{$5.80 \pm 0.14$} & \multirow{2}{*}{$\begin{array}{l}0.050 \\
\text { Not Significant }\end{array}$} \\
\hline 7th POST OP DAY & 139.77 & 9.48 & & \\
\hline
\end{tabular}

Statistical Analysis: Post Hoc Tukey HSD test. Statistically significant if $\mathrm{P}<0.05$

Comparison of preoperative, 2 day and 7 day swelling in systemically administered group (Table VII, Table VIII, Chart IV)

- A significant difference was found between preoperative $, 2^{\mathrm{ND}}, 7^{\mathrm{TH}}$ day with respect to this group.

- A statistically non-significant difference (p-value of $0.593,0.050)$ was found between $\quad$ preoperative- $7^{\text {th }}$ day and $2^{\text {nd }}-7^{\text {th }}$ day respectively

Table 9:

\begin{tabular}{|l|l|l|l|l|l|l|}
\hline PAIN (LOCAL) & MIN & MAX & MEAN & SD & $\begin{array}{l}\text { F- } \\
\text { VALUE }\end{array}$ & P VALUE \\
\hline PREOPERATIVE VALUES & 0.00 & 3.00 & 1.63 & 0.72 & 44.81 & $<0.001$ \\
\cline { 1 - 4 } 2nd POST OP DAY & 1.00 & 4.00 & 2.17 & 0.95 & & Significant \\
\cline { 1 - 5 } 7th POST OP DAY & 0.00 & 2.00 & 0.33 & 0.61 & & \\
\hline
\end{tabular}


Statistical Analysis: ANOVA one way test. Statistically significant if $\mathrm{P}<0.05$

Table 10:

\begin{tabular}{|l|l|l|l|l|}
\hline PAIN (LOCAL) & MEAN & SD & Difference & P value \\
\hline PREOPERATIVE VALUES & 1.63 & 0.72 & $0.54 \pm 0.23$ & 0.024 \\
\hline 2nd POST OP DAY & 2.17 & 0.95 & & Significant \\
\hline \multicolumn{7}{|l|}{} \\
\hline PREOPERATIVE VALUES & 1.63 & 0.72 & $1.30 \pm 0.11$ & $\begin{array}{l}<0.001 \\
\text { 7th Pignificant }\end{array}$ \\
\hline \multicolumn{2}{|l|}{0.61} & & \multirow{2}{l|}{} \\
\hline 2nd POST OP DAY & 0.33 & 0.95 & & Significant \\
\hline 7th POST OP DAY & 2.17 & 0.61 & & \\
\hline
\end{tabular}

Statistical Analysis: Post Hoc Tukey HSD test. Statistically significant if $\mathrm{P}<0.05$

Comparison of pain on preoperative, 2 day and 7 day in locally administered group(Table IX, Table Chart V).

a.A statistically significant difference was found between $2^{\text {nd }}$ day and $7^{\text {th }}$ day measurements of pain with p-value of $<0.001$

b.There was also significant difference in the the SD between the preoperative and postoperative values on $2^{\text {nd }}$ and $7^{\text {th }}$ day.

Table 13:

\begin{tabular}{|l|l|l|l|l|l|l|}
\hline PAIN (SYSTEMIC) & MIN & MAX & MEAN & SD & $\begin{array}{l}\text { F- } \\
\text { VALUE }\end{array}$ & P VALUE \\
\cline { 1 - 5 } PREOPERATIVE VALUES & 0.00 & 3.00 & 1.63 & 0.72 & 97.10 & $<0.001$ \\
\cline { 1 - 5 } 2nd POST OP DAY & 1.00 & 4.00 & 3.00 & 0.74 & & Significant \\
\hline 7th POST OP DAY & 0.00 & 2.00 & 0.43 & 0.68 & & \\
\hline
\end{tabular}

Statistical Analysis: ANOVA one way test. Statistically significant if $\mathrm{P}<0.05$

Table 14:

\begin{tabular}{|c|c|c|c|c|}
\hline PAIN (SYSTEMIC) & MEAN & SD & Difference & $\mathrm{P}$ value \\
\hline PREOPERATIVE VALUES & 1.63 & 0.72 & \multirow[t]{2}{*}{$1.37 \pm 0.02$} & \multirow{2}{*}{$\begin{array}{l}<0.001 \\
\text { Significan }\end{array}$} \\
\hline 2nd POST OP DAY & 3.00 & 0.74 & & \\
\hline PREOPERATIVE VALUES & 1.63 & 0.72 & \multirow[t]{2}{*}{$1.20 \pm 0.04$} & \multirow{2}{*}{$\begin{array}{l}<0.001 \\
\text { Significant }\end{array}$} \\
\hline 7th POST OP DAY & 0.43 & 0.68 & & \\
\hline 2nd POST OP DAY & 3.00 & 0.74 & \multirow[t]{2}{*}{$2.57 \pm 0.06$} & \multirow{2}{*}{$\begin{array}{l}<0.001 \\
\text { Significant }\end{array}$} \\
\hline 7 th POST OP DAY & 0.43 & 0.68 & & \\
\hline
\end{tabular}

Statistical Analysis: Post Hoc Tukey HSD test. Statistically significant if $\mathrm{P}<0.05$

Comparison of pain on preoperative, 2 day and 7 day in systemically administered group (Table X, Chart X).

- There was a statistically significant difference preoperatively, 2 day and 7 day with P-value of $<0.001$.

As per the T-test the done between the local and systemic group in assessing mouth opening, calculated value was 1.28 and 1.16 on $2^{\text {nd }}$ and $7^{\text {th }}$ postoperative day .which shows that local group had better recovery than systemic group.

As per the calculated value by T-test done between the local and systemic group in assessing swelling the values were 1.02 and 0.15 on $2^{\text {nd }}$ and $7^{\text {th }}$ postoperatively, which signifies that local group had recovered better than the systemic group

As per the T-test done to compare local and systemic group ,the calculated value was 1.02 and 0.15 on $2^{\text {nd }}$ and $7^{\text {th }}$ postoperative day .which shows better control of pain in local as compared to systemic group. 


\section{Discussion:-}

The acute post-operative sequelae of impacted mandibular third molar surgery are manifestations of inflammation due to tissue injury. The inflammatory reaction is an essential vital process that promotes healing of the injured tissue. The control of inflammation after the surgery needs maximum attention and therefore, the choice of the antiinflammatory agents should be directed against the control of the inflammation which further limits the intensity, decreases the post-operative sequelae like pain, swelling \& mouthopening ${ }^{46}$. In an attempt to overcome these problems, steroids, non-steroidal anti-inflammatory drugs, anti-histamines, long acting local anesthetics and antibiotics have been tried with varying degree of success.

Numerous non-steroidal anti-inflammatory drugs have been used to reduce pain, edema and improve mouth opening by inhibiting prostaglandin synthesis. These drugs suppress the post-operative pain without prominent antiinflammatory properties. Overall pain experience and morbidity were not significantly improved suggesting that there was no clinical benefit derived from interference with tissue prostaglandin synthesis at the time of surgery. The NSAIDs are dose related. Smaller doses of the drug act as analgesic. To get good anti-inflammatory action, larger doses were used.

Steroids inhibit phospholipase A2, which is responsible for conversion of membrane phospholipids into arachidonic acid. Inhibition of arachidonic acid formation in turn inhibits the cyclooxygenase and lipoxygenase pathways and blocks the arachidonic acid metabolites like prostaglandin, thromboxane, prostacyclin and leukotriene's which are responsible for inflammation. Though the anti-inflammatory potency is superior to non-steroidal anti-inflammatory drugs, steroids have its own limitations. Small dosed prolonged therapy for more than one month $(20 \mathrm{mg}$ of hydrocortisone for one month) or large dose for longer than one week, suppresses the hypothalamo-hypophyseal adrenal axis and development of Cushing's syndrome and also suppresses the signs and symptoms of the underlying disease.

Steroids are contraindicated in the conditions such as patients with active or latent peptic ulcers, Cushing's syndrome, hypertension, osteoporosis, and diabetes mellitus, and psychotic tendencies, acute or chronic infections and hepatic problems. The patients selected for this clinical trial were healthy and free from all the above contraindications. Pregnant and lactating patients were also excluded from this trial.

Currently there are many glucocorticosteroids to choose from, with differing potencies, biologic half-life and mineralocorticoid effects. Especially the synthetic steroids dexamethasone and methylprednisolone have been used extensively in oral and maxillofacial surgery for their active inflammatory and low mineralocorticoid effects ${ }^{43,55}$. In this study, dexamethasone was chosen because of its higher potency, lower sodium retaining ability and longer halflife.

A dose of $4 \mathrm{mg}$ was used equaling five times the body's normal physiology output of cortisol. The dose of steroid prescribed in this study was $1 \mathrm{ml}(4 \mathrm{mg})$ of dexamethasone injection, which was minimal and is 9.3 to 18.6 times lesser than the intensive dose.

In the present study a single dose of dexamethasone injection was selected. The normal hormonal effects associated with prolonged steroid therapy are essentially absent with single injection..

The present study evaluates the use of $4 \mathrm{mg}$ Dexamethasone by comparing intraoral injection into the submucosal site and intravenous injection into the cephalic vein in controlling the post-operative sequelae like swelling, trismus and pain. In our study submucosal injection was given into the raised mucoperiosteal flap which was selected as an ideal injection site for the local steroid administration, because the flap is anaesthetized and the injection into this region can be considered as part of the operative procedure. For the systemic administration cephalic vein was selected.

The study comprised of patients with similar bilaterally impacted mandibular third molars who were operated for surgical extraction of the impacted teeth with gap interval of 4 weeks. All the surgical procedure was carried out with single operator following similar surgical technique under local anesthesia. Routine post-operative instructions were given which included firm pressure with a gauze pack for 45 minutes. The patients were given antibiotics (Amoxicillin 500mg $8^{\text {th }}$ hourly) for 5 days and analgesics (Paracetamol 650mg $8^{\text {th }}$ hourly) for 3 days ${ }^{22,25}$. 
Each of the patient was evaluated by a single observer to score the evaluation parameters preoperatively and postoperatively on $2^{\text {nd }}$ and $7^{\text {th }}$ day. The swelling was significantly less in group-A on $2^{\text {nd }}$ and $7^{\text {th }}$ postoperative day inferring that prolonged action of dexamethasone (36-72 hrs) is quite helpful in reduction of the unwanted sequelae of swelling. It is pertinent to note that on the $7^{\text {th }}$ post-operative day when the sutures were removed, the reduction of swelling in the group-A was statistically significant compared to group-B. The post-operative mouth opening remained more in group-A when compared to group-B during second and seventh day post-operatively. Results from present investigation indicate that normal mouth opening was restored faster and the patient had better mouth opening in group-A.Statistical difference in the pain was noted which was significantly less in group-A compared to group-B. Overall the results of the present study showed a reduction in the severity of all the above mentioned parameters in group-A on $2^{\text {nd }}$ and $7^{\text {th }}$ day postoperatively indicating the effectiveness of dexamethasone in reducing inflammation. Similar results were obtained in a study by wajid et.al where they compared submucosal to intramuscular injection of dexamethasone following third molar surgery ${ }^{6}$.

\section{Summary \& Conclusion:-}

The Present study evaluated post-operative complications (Swelling, mouth opening, pain) after surgical removal of similar bilaterally impacted mandibular third molars following local or systemic administration of Dexamethasone in the Department of Oral and Maxillofacial Surgery, Vishnu Dental College, Bhimavaram.

A total of 30 healthy patients with bilateral Class II, position B mandibular third molar impaction, in the age 16-35 yrs were included in this study. One side was designated randomly as group-A to which Dexamethasone injection was administered submucosally before guttering of bone the other side with intravenous injection into the cephalic vein before the procedure was designated group-B. The surgical extractions were carried out in the same patient 4 weeks apart. Preoperative mouth openings,facial measurements and pain were noted. All the cases were reviewed on the $2^{\text {nd }}$ and $7^{\text {th }}$ day post operatively to evaluate for swelling,pain and mouth opening which were scored. Pain intensity was scored every $2^{\text {nd }}$ and $7^{\text {th }}$ day. Data obtained was put into tabloid form and statistically analyzed.

It was observed that:

- In comparing swelling and subsequent recovery, the group-A had significantly reduced swelling over group-B.

- Mouth opening was significantly better in group-A as compared to group-B.

- Pain was also less in group-A as compared to group-B.

- No patients complained of allergy to the drug or any side effects.

It was concluded that intraoperative single submucosal injection of dexamethasone $4 \mathrm{mg}$, the duration of action locally was longer, safer and significantly control the post-operative sequelae such as swelling, restricted mouth opening and pain.

Thesis pictures

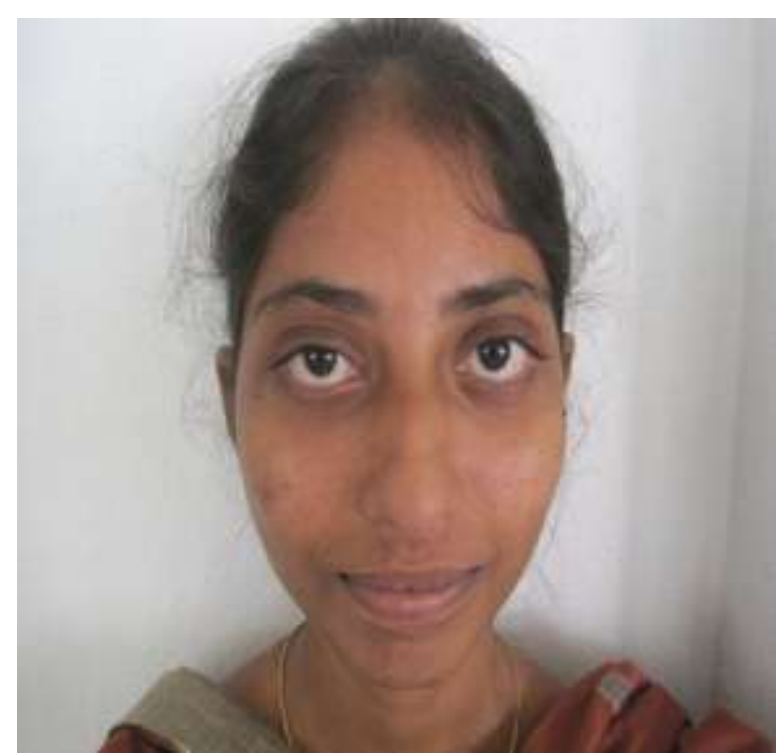



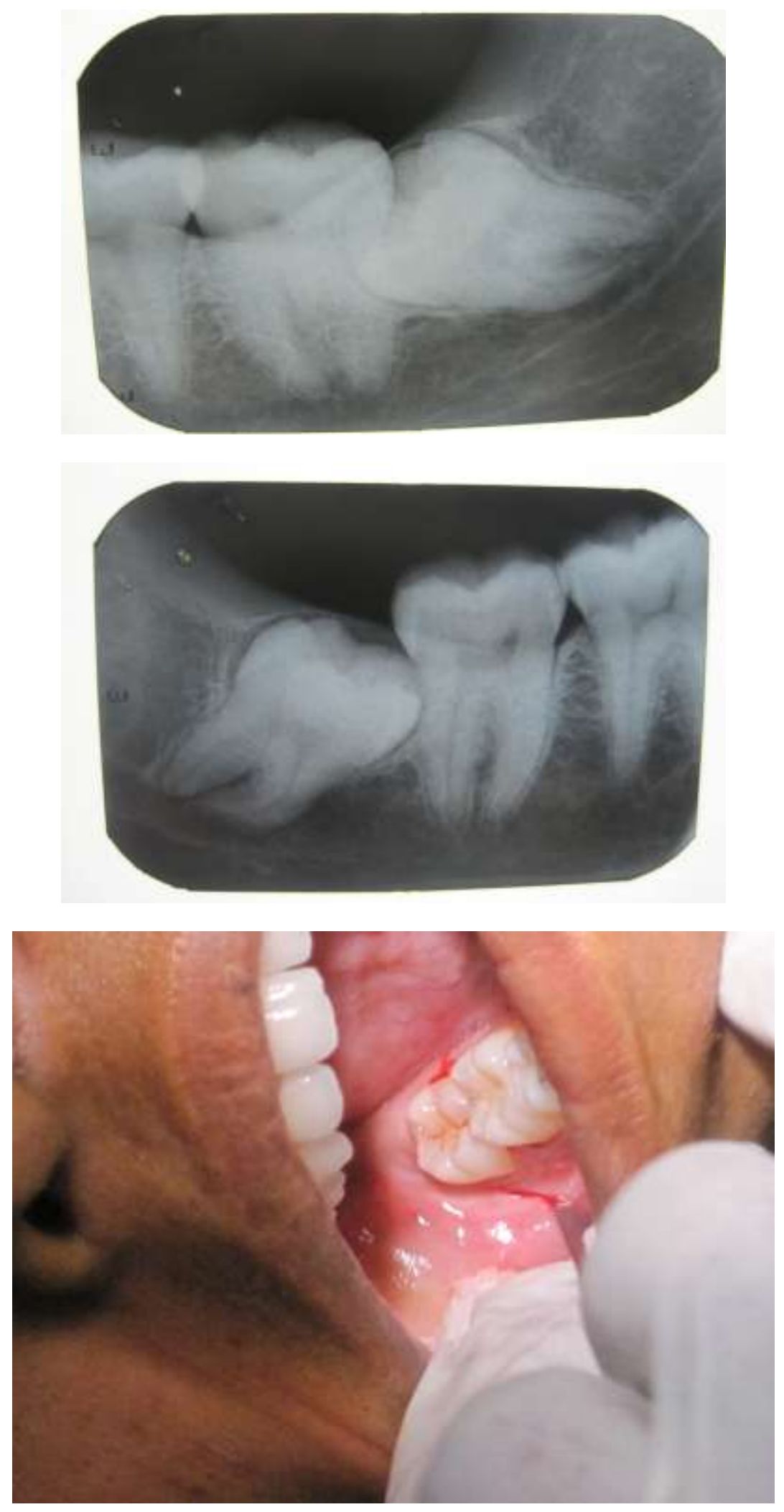

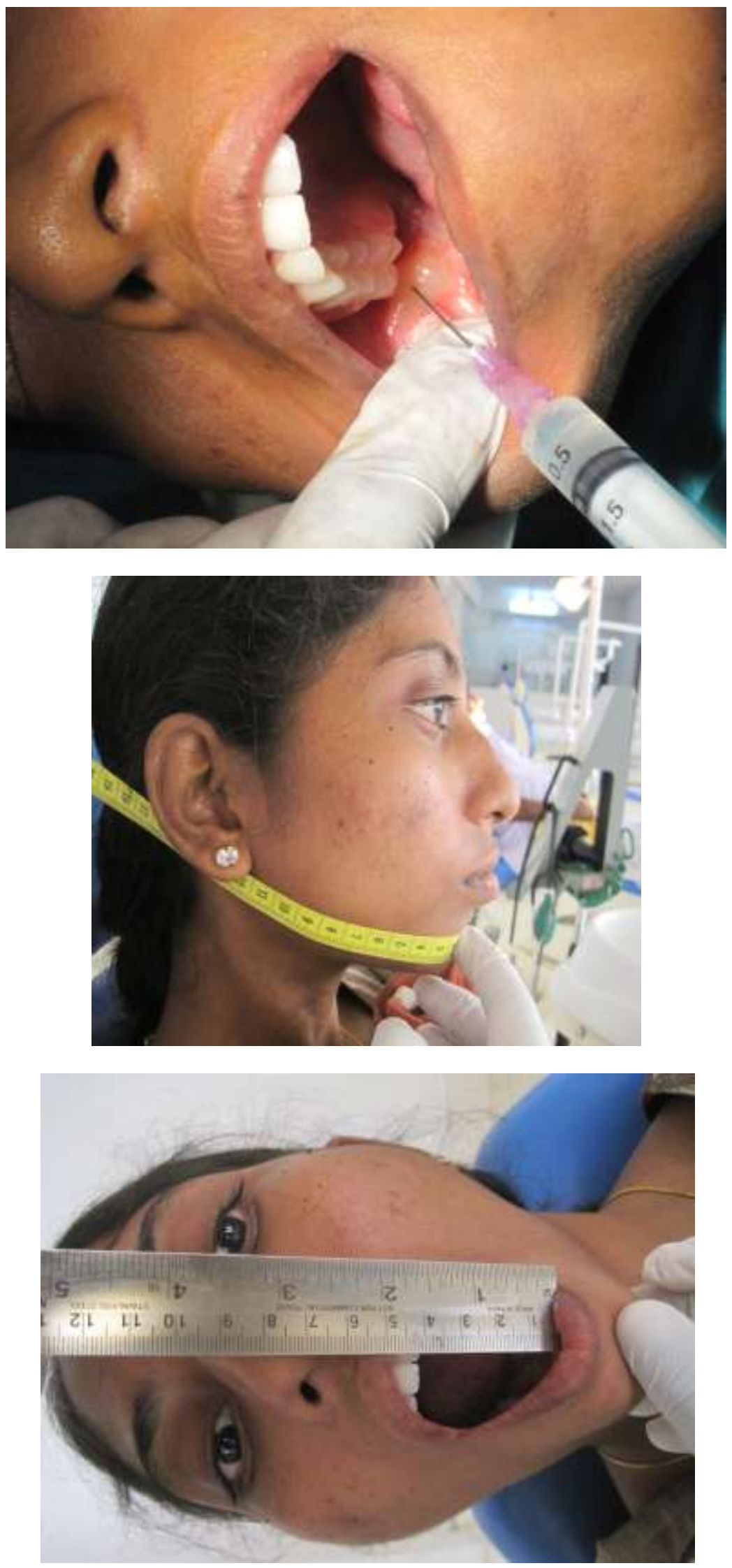
Case 2
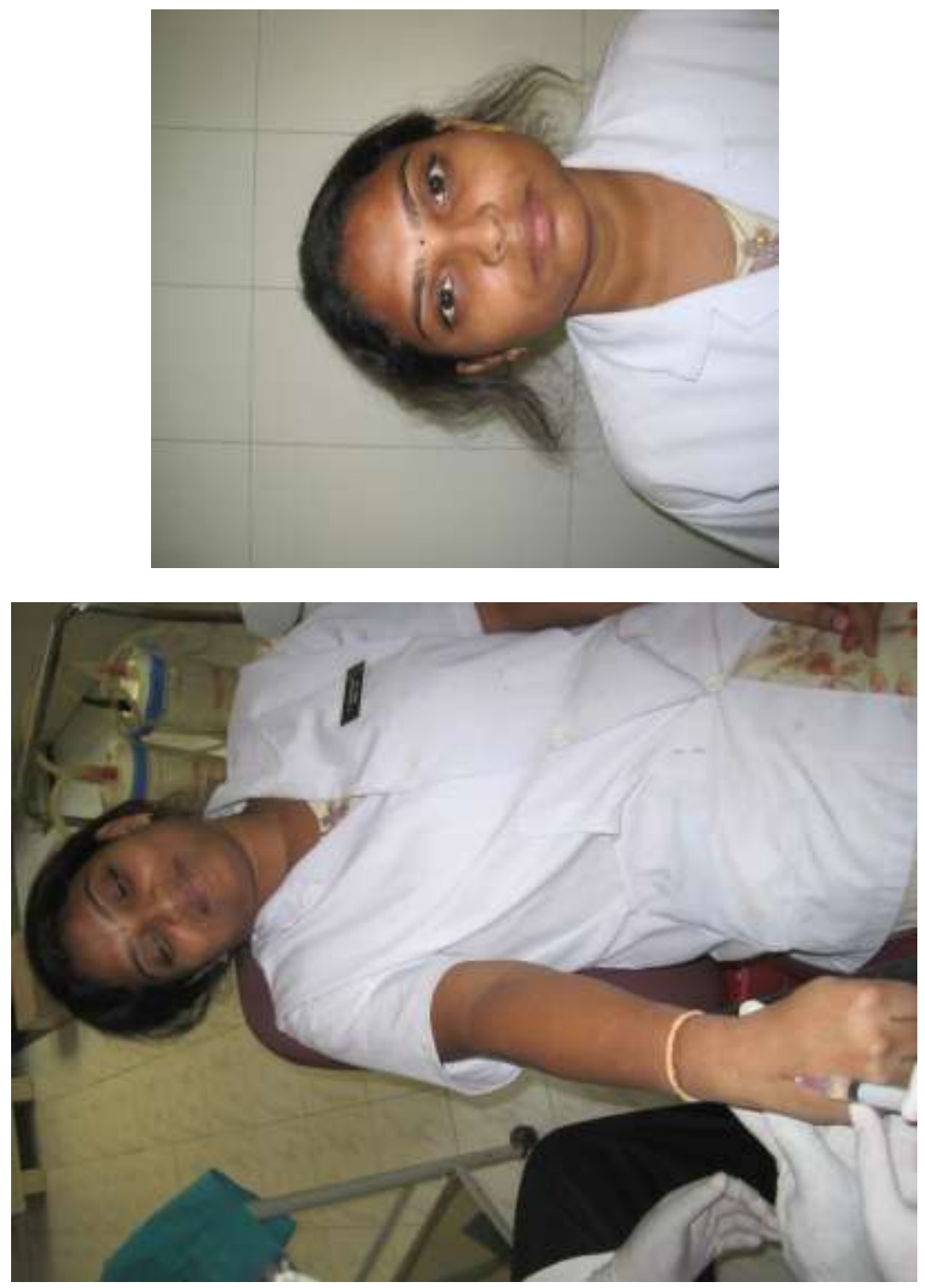

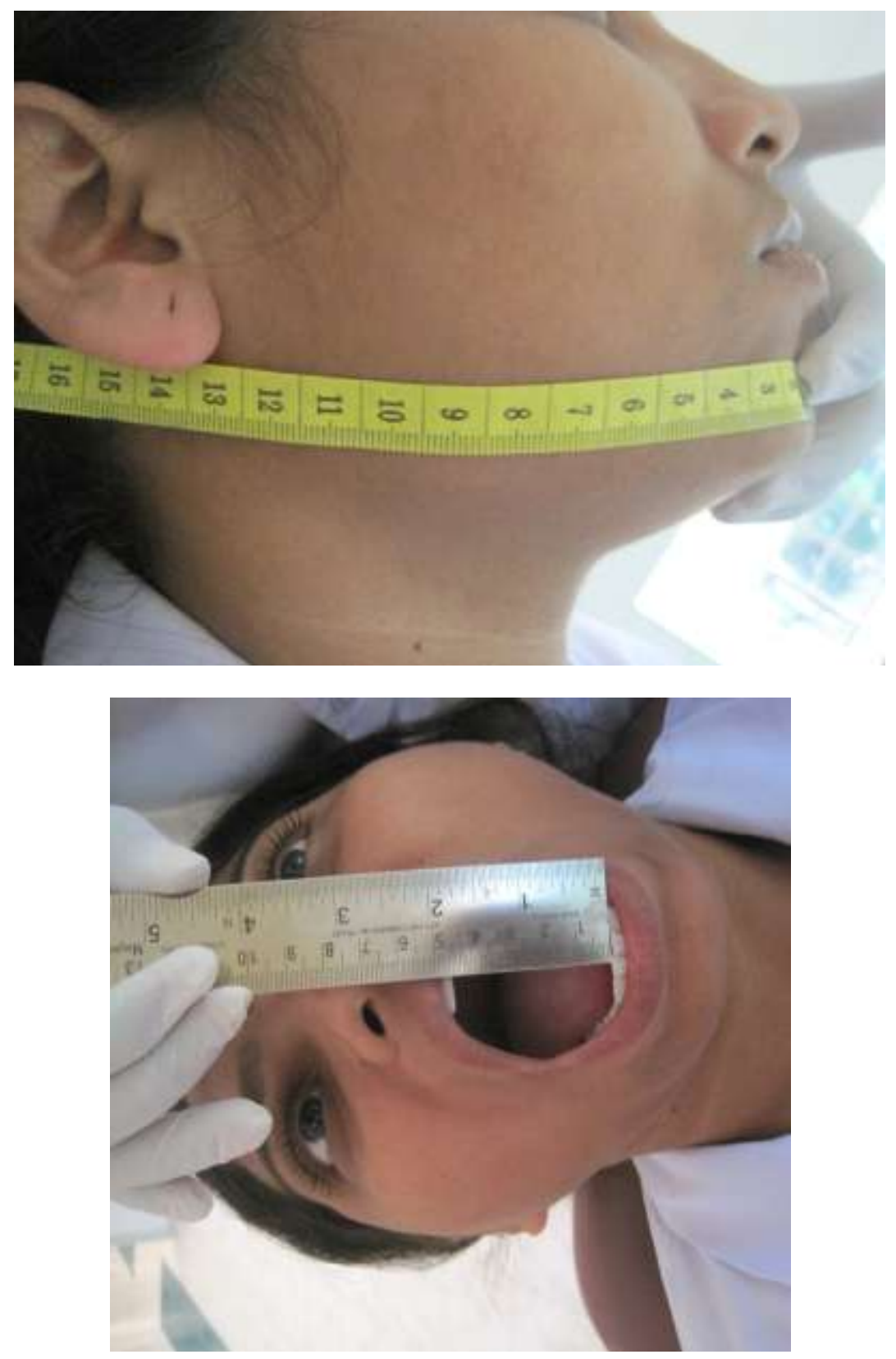

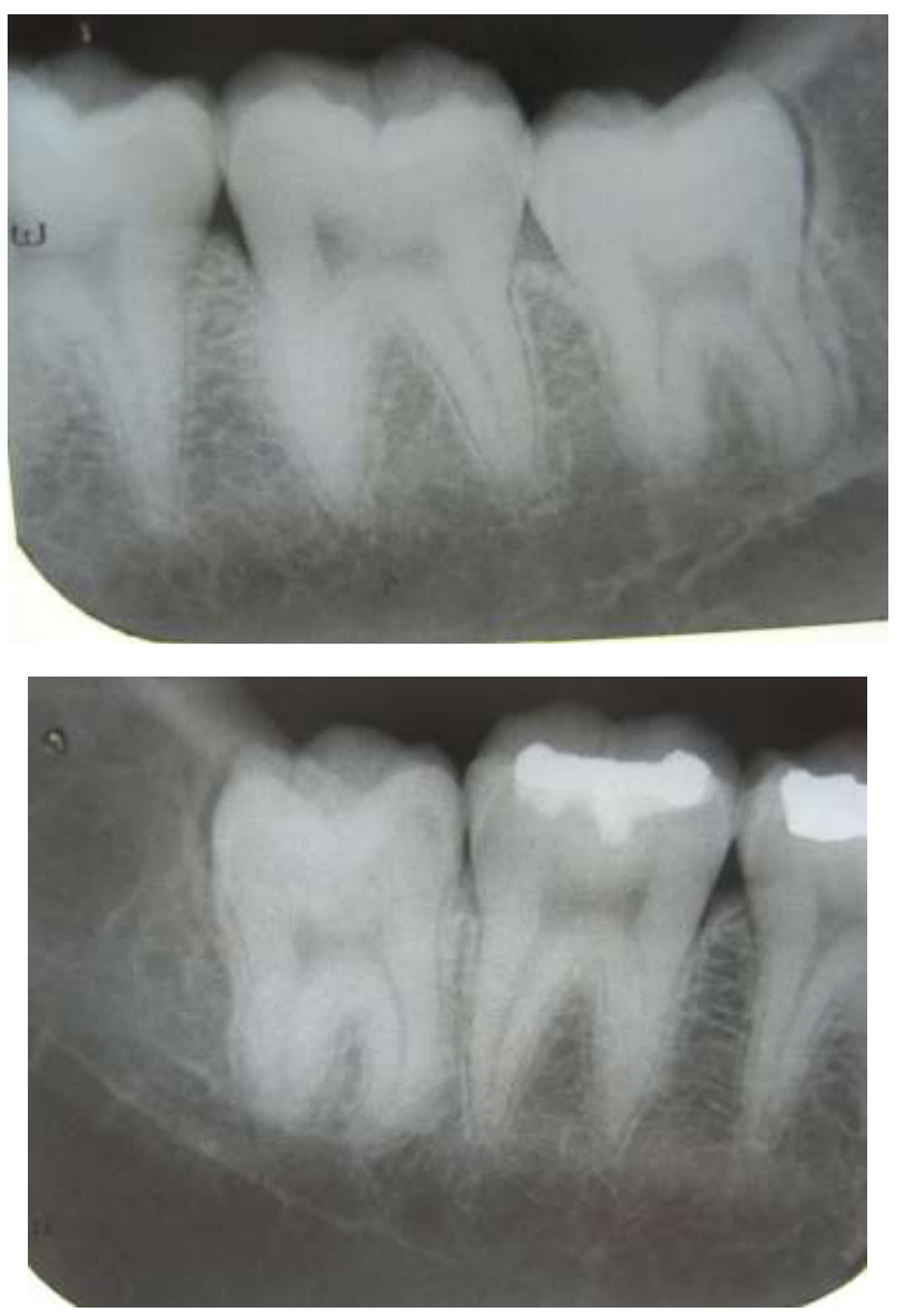